\title{
Eça de Queirós no Brasil: práticas de leitura
}

\author{
Maurício Silva \\ Universidade de São Paulo
}

\section{Introdução}

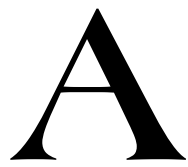

s influências estrangeiras na cultura literária brasileira sempre foram bastante intensas, a ponto de, não poucas vezes, nossa literatura nativa ter sido considerada, em algum momento de sua evolução histórica, caudatária de literaturas adventícias. Tais considerações, como se era de esperar, acabaram gerando uma curiosa nomenclatura, com o que alguns teóricos e estudiosos do assunto procuraram definir um conjunto de obras literárias produzidas no Brasil durante um determinado período de nossa história, como é o caso da Literatura Luso-Brasileira.

Embora a intersecção entre as literaturas brasileira e portuguesa verificada desde longa data - tivesse perdido em intensidade para nossas relações com a literatura francesa, sobretudo a partir de meados do século XIX, não se pode negar que Brasil e Portugal foram e têm sido parceiros contínuos em suas relações culturais, uma parceria, aliás, que alcança até mesmo instâncias que, se não fazem parte da literatura stricto sensu, participam do conjunto de elementos socioculturais responsáveis, no seu conjunto, por um suporte efetivo à prática literária, além de permitirem de forma distintiva a concreção da legibilidade: as escolas, editoras, tipografias, academias, livrarias etc.

Tanto a questão da literatura propriamente dita (e a problemática da influência literária que lhe é pertinente e inerente) quanto a dos suportes materiais da legibilidade, a que aludimos aqui, remetem à abordagem de um assunto que, embora pareça distante dos temas referidos, é na verdade um pressuposto para seu entendimento: a questão da leitura, a qual pressupõe - sobretudo no Brasil da passagem do século - a abordagem de pelo menos dois conceitos que lhe são pertinentes: o 
analfabetismo que, vez por outra, se apresenta aos olhos dos historiadores, como endêmico; e a produção editorial, que se consolida no país em meio a uma série de percalços.

Em ambos os casos, é possível perceber um esforço intensivo por parte da crítica e da historiografia especializada para desfazer equívocos, expor novos conceitos e critérios de avaliação do problema, levantar dados relativos às problemáticas que lhe são inerentes, enfim, esclarecer os pontos obscuros e/ou ainda não devidamente estudados. ${ }^{1}$

Com efeito, no que concerne ao analfabetismo, não é difícil detectar - de um modo geral - uma certa atmosfera pessimista por parte dos intelectuais do período, já que os mesmos debitavam o propalado desinteresse pela literatura à falta de educação letrada da maioria da população brasileira. Semelhante diagnóstico, contudo, pode esconder alguns fatos menos evidentes, mas que - no final das contas - merecem ser levados em consideração, para os quais, aliás, esses mesmos intelectuais parecem não ter dado a devida importância ou não ter se conscientizado plenamente: em primeiro lugar, a despeito do pessimismo de que a elite intelectual estava imbuída, deve-se salientar que, de diversas maneiras, o analfabetismo reinante acabou se tornando uma referência à produção literária do período, que se manifestará, muitas vezes, em consonância com as reais condições de legibilidade da população, como aliás já afirmara um dos estudiosos do período, para quem o analfabetismo teria dado "o tom geral à atividade intelectual no Brasil nesse período, (pois) é a partir dele que os escritores assumem as suas posições, é em função dele que definem os seus propósitos". ${ }^{2}$

Não custa lembrar ainda que a realização de um processo amplo de alfabetização não reverte - como talvez pensassem os mesmos intelectuais do período - em ganhos reais para a literatura erudita, muitas vezes redundando tal processo num aumento significativo no grau de recepção da cultura de massa, como igualmente já salientara Antônio Cândido ao tratar da alfabetização nos dias presentes:

\footnotetext{
${ }^{1}$ Consultar, tanto para a questão do analfabetismo quanto para a questão da produção editorial do período, os seguintes estudos: SODRÉ, 1977; BAHIA, 1990; LAJOLO \& ZILBERMAN, 1996; GOMES, 1983; e NAGLE, 1976.

${ }^{2}$ SEVCENKO, n. 14, p. 80-83, 1982.
} 


\begin{abstract}
"na maioria dos nossos países há grandes massas ainda fora do alcance da literatura erudita, mergulhando numa etapa folclórica de comunicação oral. Quando alfabetizadas e absorvidas pelo processo de urbanização, passam para o domínio do rádio, da televisão, da história em quadrinhos, constituindo a base de uma cultura de massa. Daí a alfabetização não aumentar proporcionalmente o número de leitores da literatura (...); mas atirar os alfabetizados, junto com os analfabetos, diretamente da fase folclórica para essa espécie de folclore urbano que é a cultura massificada". ${ }^{3}$
\end{abstract}

No que concerne à produção editorial, podemos perceber, sintomaticamente, uma atmosfera pessimista similar à que se impunha diante da problemática da alfabetização. Em primeiro lugar, é preciso lembrar que se vivia um período de particular efervescência cultural, em que a imprensa era cada vez mais requisitada, em que seu poder de divulgação cultural era cada vez mais intenso e em que se verificou um vasto processo de desenvolvimento e modernização da mesma. ${ }^{4}$ Isso tudo redundava, evidentemente, numa ampla concorrência entre o jornalismo e a produção livresca, com uma sensível desvantagem para o livro, mais caro, extenso e profundo do que o jornal.

E, no entanto, lia-se bastante naquela época. Apesar do pessimismo generalizado, decorrente - em substância - tanto do analfabetismo quanto da decadência da produção editorial livresca, havia uma parcela considerável da população que se dispunha a ler com todas as ressalvas práticas e intelectuais que uma leitura pressupõe. Uma parcela considerável, não exatamente pela quantidade de seus representantes, mas antes pela qualidade dos mesmos: trata-se dos intelectuais da passagem do século que, pelas condições peculiares em que se apresentava o meio cultural brasileiro, emergiam não apenas como os principais produtores de textos

${ }^{3}$ CÂNDIDO, 1989. p. 140-162. Na época em estudo, evidentemente, a cultura massificada, à qual os alfabetizados deveriam aderir peremptoriamente, era representada por outros veículos de divulgação - como os jornais e periódicos mundanos - e, principalmente, por outros gêneros literários - como os folhetins (Cf. MEYER, 1996; MEYER, 1998; MEYER, n. 14, p. 7-22, 1982). ${ }^{4}$ Cf. SODRÉ, 1977; BAHIA, 1990; MELO, 1973; ALBERT \& TERROU, 1990; BOIVIN, 1949. 
literários do período, mas também - e, quiçá, principalmente - como seus mais recorrentes consumidores, ${ }^{5}$ motivo pelo qual serão alçados neste estudo como principais testemunhas das práticas de leitura da ficção de Eça de Queirós no Brasil desse período.

\section{Recepção de Eça de Queirós no Brasil}

Muitos foram os autores estrangeiros que influenciaram direta ou indiretamente a produção literária nacional. Entre todos eles, contudo, merece destaque, já por se tratar de um grande nome da literatura em língua portuguesa, já por ter se tornado uma das figuras mais assiduamente cultuadas no Brasil, o romancista português Eça de Queirós.

A recepção de Eça de Queirós e de sua vasta e polêmica produção ficcional, no Brasil, articula-se diretamente com a vida literária aqui desenvolvida no último quartel do século XIX e primeiras décadas do século XX. Embora seus primeiros escritos tivessem tido várias contrafações nalguns dos principais estados nacionais, sua verdadeira recepção começa pelo viés da polêmica: primeiro, com a divulgação, no país, de seus indefectíveis panfletos intitulados As Farpas (1870-1871), ao lado do companheiro Ramalho Ortigão; segundo, com a crítica de Machado de Assis, nas páginas de O Cruzeiro (1878), de seu romance $O$ Crime do Padre Amaro, ambos os acontecimentos concorrendo para que o romancista português adquirisse fama larga e perpétua. ${ }^{6}$

Venerado pela maior parte dos autores da época, Eça de Queirós teve reconhecimento imediato pela crítica, tendo sido publicado no Brasil alguns de seus principais estudos críticos, como os de Miguel Melo, Viana Moog ou Álvaro Lins, o que atesta, ainda uma vez, o deslumbramento causado por seus romances picantes e inovadores. ${ }^{7}$

\footnotetext{
${ }^{5}$ Para uma visada geral das atividades profissionais e intelectuais das mais representativas figuras da intelligentsia brasileira, consultar MACHADO NETO, 1973; e MICELI, 1977.

${ }^{6}$ Para a questão da recepção de Eça no Brasil ligada à polêmica d'As Farpas, consultar MEDINA, 2000; e ligada à polêmica entre com Machado de Assis, consultar ROSA, 1979.
}

${ }^{7}$ Cf. FARO, 1977. 
Tendo exercido uma influência literária direta e efetiva sobre alguns dos mais renomados autores de nossa literatura, Eça de Queirós foi seguido também de modo circunstancial por alguns escritores brasileiros menores, como Adoasto de Godoi (que escreveu crônicas para $A$ Imprensa sob o pseudônimo de Carlos Eduardo), Antonio Torres (que publicou sua Correspondência de João Epíscopo, numa possível referência à Correspondência de Fradique Mendes), Carlos de Laet (que publicou crônicas no Última Hora sob o pseudônimo de João da Ega) ou José Madeira de Freitas (humorista que se notabilizou com o pseudônimo de Mendes Fradique, referência ironicamente invertida à célebre personagem de Eça). ${ }^{8}$

\section{Eça de Queirós no Brasil: práticas de leitura}

A leitura de Eça de Queirós no Brasil - mais do que uma simples atividade lúdica - constitui-se uma prática singular, que aponta para os modos como seus romances eram recebidos e interpretados por aqui. Trata-se, assim, de uma prática que, ao se consolidar, vai construindo a próprio fisionomia literária do romancista português entre nós, pois, como já afirmara com sagacidade Jean Marie Goulemot,

"a leitura é sempre produção de sentido (...) é uma revelação pontual de uma polissemia do texto literário. A situação da leitura é, em decorrência disso, a revelação de uma das virtualidades significantes do texto". ${ }^{9}$

Com efeito, é a partir da leitura que os textos adquirem sua plenitude enquanto textos literários, ${ }^{10}$ o que concede à obra de Eça de Queirós uma importância para além de seus significados intrinsecamente estéticos. É essa importância, aliás, que queremos resgatar por meio de leitores que - no calor da hora - testemunharam a chegada de sua produção literária no país.

\footnotetext{
${ }^{8}$ Consultar MONTEIRO, n. 269, p. 22-23/52, set. 1941; BELLO, 1917, p. 15-31; e SILVA, v. XXII, n. 60, p. 119-122, abr. 1996.

${ }_{9}^{9}$ GOULEMOT, 1996. p. 107-116.

${ }^{10}$ Cf. LAJOLO, 1988. p. 87-99.
} 
Um roteiro seguro para se pensar o quanto Eça de Queirós era lido no Brasil é, sem dúvida nenhuma, um sugestivo livro de João do Rio, intitulado O Momento Literário. ${ }^{11}$ Publicado em 1907, constituiu-se, originalmente, numa série de reportagens impressas nas páginas da Gazeta de Notícias, entre 1905 e 1907, sob a forma de enquetes. A inspiração, como era comum acontecer - mormente no caso de João do Rio - vinha da França, na obra Enquête sur l'Évolution Litteraire (1891), de Jules Huret. Em suas reportagens para a Gazeta de Notícias, João do Rio procurou entrevistar aqueles que considerava os principais escritores e intelectuais da época, arrolando uma série de perguntas que repetia a cada um deles, quase todas voltadas direta ou indiretamente para suas preferências em termos de leitura.

Um levantamento estatístico sobre as respostas recolhidas pela enquete de João do Rio já nos indica alguns resultados significativos. Numa amostragem geral sobre as preferências dos intelectuais brasileiros da época, por exemplo, O Momento Literário revela-nos, em primeiro lugar, que as obras mais lidas provinham da Literatura Francesa, fato compreensível para uma época em que tudo o que vinha da França fazia sucesso indiscutível, sobretudo no âmbito cultural e, particularmente, no literário. ${ }^{12}$ A Literatura Francesa $(23,7 \%)$ era, por isso, ainda mais lida do que nossa co-irmã, a Literatura Portuguesa $(8,6 \%)$ que, como aludimos no início, perdia cada vez mais espaço para a expressão gaulesa, conforme esclarece o gráfico abaixo:

Entre aquelas agrupadas sob a denominação de "outras" (20,3\%), contavam-se as de origem clássica, isto é, gregas e latinas (5,9\%), inglesa $(3,6 \%)$, alemã $(3,2 \%)$, italiana (3\%), espanhola $(1,9 \%)$, russa $(0,9 \%)$, norteamericana $(0,7 \%)$ e diversas outras de origem não-especificada ou que não figuram em nosso quadro de forma singularizada pela pouca freqüência com que são citadas (1,1\%).

Em relação à amostragem de autores e no que concerne especificamente à Literatura Portuguesa, constata-se que o mais lido é, sintomaticamente, Eça de Queirós (5,3\%), seguido de Camões (3,7\%), Alexandre

${ }^{11}$ RIO, 1994.

${ }^{12}$ A bibliografia sobre o assunto é extensa, podendo-se citar, a título de exemplo, para um panorama das relações culturais franco-brasileiras, RIVAS, 1995; CARELLI, 1994; LIMA-BARBOSA, 1923; e CARELLI; THÉRY; ZANTMAN, 1987. 
Herculano (2,6\%), Almeida Garret (2,1\%) e outros. Fialho de Almeida, nome muito discutido na época, foi um dos menos citados $(0,5 \%)$, ao lado de outras figuras completamente apagadas.

Temos, assim, o seguinte esquema, sendo que os "outros" correspondem agora a 14 autores portugueses:

Os dados estatísticos acima expostos, ilustrados por seus respectivos gráficos, guardam alguns fatos importantes e sugestivos, mas sobetudo atestam a indefectível presença de Eça de Queirós no Brasil, como o mais lido autor português da passagem do século.

Não bastasse a enquete de João do Rio, houve ainda uma outra pesquisa, em 1893, realizada pela revista A Semana, de Valentim Magalhães e Max Fleiuss, acerca das preferências de leitura não mais dos intelectuais brasileiros, mas da população em geral. Perguntando sobre os melhores romances escritos em Língua Portuguesa de todos os tempos, na opinião dos leitores, o célebre periódico colheu como resultado - o que já era de se esperar, pelo que vimos expondo até agora - a vitória inconteste de Eça de Queirós, que tivera três de seus romances como

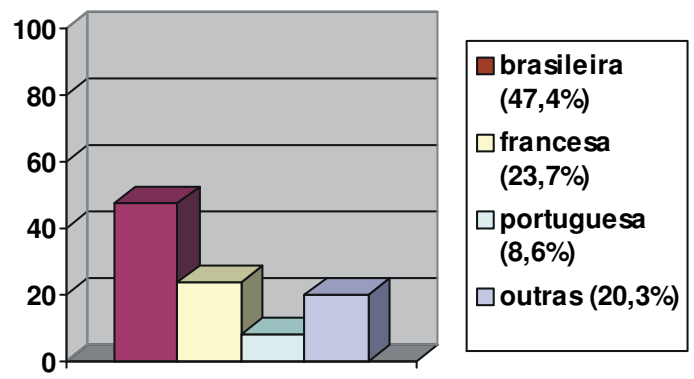

sendo os mais bem votados: Os Maias (primeiro lugar), O Primo Basílio (segundo lugar) e A Relíquia (quarto lugar); em terceiro e quinto lugares, tínhamos dois romances de Machado de Assis, respectivamente Memórias Póstumas de Brás Cubas e A Mão e a Luva. ${ }^{13}$

Embora o resultado de tais pesquisas seja irretorquível, no que concerne à importância adquirida pela obra de Eça de Queirós no cenário cultural brasileiro, resta saber ainda como se davam de fato as práticas de leitura que norteavam essa sua massiva presença, o que pode ser percebido em alguns testemunhos deixados por seus diversos leitores.

${ }^{13}$ MARTINS, v. IV, 1977/1978, p. 423 et passim. 
Não resta dúvida que os romances de Eça de Queirós, desde que entraram no Brasil, fizeram um sucesso retumbante. Raimundo de Menezes, biógrafo das celebridades literárias da passagem do século, lembra, por exemplo, que a chegada dos romances O Crime do Padre Amaro e O Primo Basílio no país foi marcada pelo mais absoluto e contagiante entusiasmo, um entusiasmo aliás confirmado por Brito Broca, para quem nossa Belle Époque fora tomada subitamente pela doença do basilismo, subproduto de uma mania ainda maior, a do ecismo. ${ }^{14}$

Lido tanto pela pequena burguesia carioca letrada quanto por nossos mais eminentes intelectuais do período, os livros de Eça de Queirós provocaram - mais do que entusiasmo - verdadeiros escândalos, dando
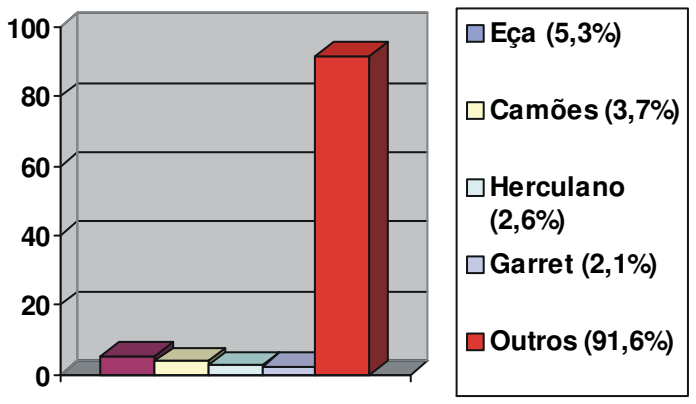

ensejo a todos tipo de controvérsias. Personalidades as mais diferentes leram seus livros, fazendo referências ora positivas, como Coelho Neto, em discurso pronunciado num banquete oferecido a ele pelos sócios da Livraria Chardron, em 1923; ora negativas, como Lima Barreto que, em seu Diário Íntimo, anota passagem em que compara desabonadoramente o estilo do romancista português ao do nativo Raul Pompéia. ${ }^{15}$

De qualquer maneira, o entusiasmo prevalecia sobre a repulsa, levando, inclusive, muitos autores brasileiros a procurar, em Paris, conhecer pessoalmente a figura do célebre romancista. ${ }^{16}$

\footnotetext{
${ }^{14}$ Cf. MENEZES, 1958; BROCA, 1991; e BROCA, 1960.

${ }^{15}$ Respectivamente, NETO, 1928; e BARRETO, 1953.

${ }^{16}$ Consultar BROCA, 1993, p. 138 et passim. Olavo Bilac narra, na Gazeta de Notícias, em 1900, seu primeiro e venturoso encontro com Eça de Queirós, em Paris (BILAC, 1996. p. 65-74).
} 
De acordo com a já aludida pesquisa realizada pela revista $A$ Semana, em 1893, as obras de Eça mais admiradas eram Os Maias, O Primo Basílio e A Relíquia. Há fortes indícios, pelos testemunhos que conseguimos levantar, de que não foram as únicas lidas com entusiasmo, nem a avidez pela leitura teria se dado nessa ordem. Mais do que qualquer outro romance, O Primo Basílio parece ter sido o mais consumido pelos brasileiros, possivelmente seguido por O Crime do Padre Amaro. Sobre A Relíquia, há referências à sua leitura, por exemplo, num romance de Gonzaga Duque, em que dois personagens travam um diálogo acerca da recente leitura do referido romance ("li a obra que me inculcou... $A$ Reliquia..."); o mesmo se dá num singular "diário" em que Júlia Lopes de Almeida registra sua viagem pelo Rio Grande do Sul, quando, numa noite de frio, relembra passagens do romance ("a maravilhosa página de Eça na sua incomparavel Riliquia"). ${ }^{17}$ Indício seguro de que A Relíquia era, ainda, um livro bastante conhecido pelo público brasileiro é o fato ressaltado com ironia por José Veríssimo - de grande parte de nossos literatos colocarem em seus próprios livros a epígrafe que Eça criara para o romance referido ("Sobre a nudez forte da verdade, o manto diáfano da fantasia"), numa verdadeira obsessão pela "estafada epígrafe". ${ }^{18}$

Menos lidos, A Ilustre Casa de Ramires e A Cidade e as Serras recebem pouca atenção por parte de comentadores/leitores, enquanto que Os Maias são lembrados mais por meio de personagens ilustres, como João da Ega, Dâmaso ou Carlos da Maia. Há pelo menos uma referência à leitura dos contos de Eça: em suas memórias, Laura Oliveira Rodrigo Octávio, sobrinha do intelectual brasileiro Rodrigo Octávio - advogado ilustre e um dos fundadores da Academia Brasileira de Letras -, lembra que, na infância, ouvia sua irmã ler, "em voz alta", os contos do já famoso escritor lusitano. ${ }^{19}$

Não há, contudo, outras obras de Eça de Queirós - com exceção, talvez, de suas impagáveis As Farpas - que tenham sido tão lidas, comentadas e criticadas quanto os romance O Crime do Padre Amaro e O Primo Basílio.

\footnotetext{
${ }^{17}$ DUQUE, 1973, p. 229; e ALMEIDA, 1920. p. 108.

${ }^{18}$ VERÍSSIMO, 1936, p. 20 et passim.

${ }^{19}$ OCTÁVIO, 1994. p. 41.
} 
Publicado em 1878, O Crime do Padre Amaro foi, ainda no mesmo ano, objeto de uma minuciosa leitura por parte de nada menos do que Machado de Assis, que, nas páginas de O Cruzeiro, trava com o romancista português acirrada e célebre batalha literária. ${ }^{20}$ Quanto a O Primo Basilio, informa-nos Brito Broca, em estudo já citado, ${ }^{21}$ que se travou, nas páginas da Gazeta de Notícias, exacerbado debate, condimentado por impiedosas ironias por parte dos articulistas. O romance foi, de fato, um escândalo, sendo acusado, entre outras coisas, de pornográfico. Avivando ainda mais os desentendimentos em torno da obra, Antônio Torres escreve uma crônica em que reclama da profusão, no Brasil, de poesias plangentes uma verdadeira "algaravia de colegial cheio de sentimentalismo", resultado de um fenômeno a que chama de bacillus lyricus, título da crônica -, e afirma que quando encontra uma jovem que "estremece, sacode-se, arfa e tem o corpo todo a delirar", com certeza ela "estará a ler em êxtase" ou Les Demi-Vierges de Marcel Prevost ou O Primo Basílio de Eça de Queirós, precisamente aquela cena em que o ilustre lusitano nos descreve "o canalha do romance, durante as extravagâncias com a prima, na inequívoca e supercivilizada posição de quem se levanta de estar de joelhos, ainda meio incendiado, alisando os bigodes e lambendo os beiços". ${ }^{22}$

É desse mesmo romance que falava o crítico e literato Gonzaga Duque - em crônica que um dia tivemos em mãos ${ }^{23}$-, ao testemunhar seu primeiro contato com a obra de Eça de Queirós, cujo O Primo Basílio teria sido lido por ele de uma única vez, madrugada adentro, sem que conseguisse largar do livro antes que a história finalizasse.

${ }^{20}$ É ampla a bibliografia sobre a polêmica Machado/Eça, o que gerou uma tendência crítica voltada à comparação obsessiva entre os dois autores. Cf. ROSA, 1979; PEREIRA, n. 08, p. 474-478, jul. 1939; SIMOES, Ano IV, n. 37, p. 1-3, jul. 1941; MIRANDA, n. 485, p. 52-60, nov. 1945.

${ }^{21}$ BROCA, 1991. p. 73 et passim.

22 TORRES, 1925. p. 42.

${ }^{23}$ A crônica - inédita em livro e que certa vez consultamos, infelizmente sem ter tido o cuidado de referenciá-la adequadamente - fora escrita por Gonzaga Duque no começo do século, provavelmente em A Cultura Acadêmica, periódico publicado no Recife, possivelmente a partir de 1904. 
Não causam espanto, portanto, testemunhos como o de Thomaz Lopes, ao lembrar - num patético exagero -, a respeito de Eça de Queirós, que "toda uma geração sabia de cor os seus livros", ${ }^{4}$ afirmação que atesta, de modo emblemático e insofismável, o sucesso das obras queirosianas, cuja leitura fora assumida como prática constante durante um extenso período de nossa vida cultural.

\section{Referências Bibliográficas}

ALBERT, P.; TERROU, F. História da Imprensa. São Paulo: Martins Fontes, 1990. ALMEIDA, Júlia Lopes de. Jornadas no meu país. Rio de Janeiro: Francisco Alves, 1920.

BAHIA, Juarez. Jornal, história e técnica. História da Imprensa Brasileira. São Paulo: Ática, 1990.

BARRETO, Lima. Diário íntimo. Rio de Janeiro: Mérito, 1953.

BELLO, José Maria. As idolatrias litterarias. Eça de Queiroz e a sua influência no Brasil. Estudos Críticos. Rio de Janeiro: Jacintho Ribeiro dos Santos, 1917, p. $15-31$.

BILAC, Olavo. Vossa Insolência (org. Antônio Dimas). São Paulo: Companhia das Letras, 1996.

BOIVIN, Émile. Histoire du Journalisme. Paris: Presses Universitaires de France, 1949.

BROCA, Brito. Teatro das Letras. Campinas: Unicamp, 1993.

BROCA, Brito. Naturalistas, parnasianos e dacadistas. Vida literária do realismo ao pré-modernismo. Campinas: Unicamp, 1991.

BROCA, Brito. A vida literária no Brasil. 1900. Rio de Janeiro: José Olympio, 1960.

CÂNDIDO, Antonio. Literatura e Subdesenvolvimento. A Educação pela noite e outros ensaios. São Paulo: Ática, 1989, p. 140-162.

CARELLI, Mário. Culturas Cruzadas. Intercâmbios Culturais entre França e Brasil. Campinas: Papirus, 1994.

${ }^{24}$ LOPES, 1911. p. 12. 
CARELLI, M.; THÉRY, H.; ZANTMAN, A. France-Brésil: Bilan pour une Relance. [s.1.], Entente, 1987.

DUQUE, Gonzaga. Mocidade morta. São Paulo: Editora Três, 1973.

FARO, Arnaldo. Eça e o Brasil. São Paulo: Nacional/Edusp, 1977.

GOMES, Sônia de Conti. Bibliotecas e sociedade na Primeira República. São Paulo: Pioneira, 1983.

GOULEMOT, Jean Marie. Da leitura como produção de sentidos. In: CHARTIER, Roger (Org.). Práticas de leitura. São Paulo: Estação Liberdade, 1996, p. 107-116.

LAJOLO, Marisa; ZILBERMAN, Regina. A formação da leitura no Brasil. São Paulo: Ática, 1996.

LAJOLO. Marisa. Leitura-literatura: mais do que uma rima, menos do que uma solução. In: ZILBERMAN, R.; SILVA, Ezequiel T. (Org.). Leitura. Perspectivas interdisciplinares. São Paulo: Ática, 1988, p. 87-99.

LIMA-BARBOSA, Mário de. Les Français dans l'Histoire du Brésil. Paris: Blanchard, 1923.

LOPES, Thomaz. Sete Soes. Chronicas. Rio de Janeiro: Garnier, 1911.

MACHADO NETO, A. L. Estrutura social da república das letras (Sociologia da vida intelectual brasileira. 1870-1930). São Paulo: Grijalbo/Edusp, 1973.

MARTINS, Wilson. História da inteligência brasileira (1877-1896). São Paulo: Cultrix, v. IV, 1977/1978.

MEDINA, João. Eça de Queirós Antibrasileiro? Bauru: Edusc, 2000.

MELO, José Marques de. Sociologia da Imprensa Brasileira. Petrópolis: Vozes, 1973.

MENEZES, Raimundo de. Aluísio Azevedo. Uma Vida de Romance. São Paulo: Martins, 1958.

MEYER, Marlyse. Folhetim. Uma História. São Paulo: Companhia das Letras, 1996.

MEYER, Marlyse. As mil faces de um herói-canalha e outros ensaios. Rio de Janeiro: UFRJ, 1998.

MEYER, Marlyse. Folhetim para Almanaque ou Rocambole, A Ilíada de Realejo. Almanaque. São Paulo, Brasiliense, n. 14, p. 7-22, 1982.

MICELI, Sérgio. Poder, sexo e letras na República Velha (Estudo Clínico dos Anatolianos). São Paulo: Perspectiva, 1977 
MIRANDA, Hermínio de. Eça de Queiroz e Machado de Assis. Vamos Ler, Rio de Janeiro, n. 485, p. 52/60, nov. 1945.

MONTEIRO, Mário. Eça de Queiroz e o Brasil. Vamos Ler. Rio de Janeiro, n. 269, p. 22-23/52, set. 1941.

NAGLE, Jorge. Educação e sociedade na Primeira República. São Paulo: EPU, 1976.

NETO, Coelho. Livro de Prata. São Paulo: Livraria Liberdade, 1928.

OCTÁVIO, Laura Oliveira Rodrigo. Elos de uma corrente, seguidos de novos elos. Rio de Janeiro: Civilização Brasileira, 1994.

PEREIRA, Lúcia Miguel. Machado de Assis e Eça de Queiroz. Revista de Portugal. Coimbra, n. 08, p. 474-478, jul. 1939.

RIO, João do. O momento literário. Rio de Janeiro: Fundação Biblioteca Nacional/Departamento Nacional do Livro, 1994.

RIVAS, Pierre. Encontro entre literaturas. França-Portugal-Brasil. São Paulo: Hucitec, 1995.

ROSA, Alberto Machado da. Eça, discípulo de Machado? Um Estudo sobre Eça de Queirós. Lisboa: Presença, 1979.

SEVCENKO, Nicolau. O fardo do homem culto: literatura e analfabetismo no Prelúdio Republicano. Almanaque. Cadernos de Literatura e Ensaio, São Paulo, n. 14, p. 80-83, 1982.

SILVA Maurício. Influências queirosianas. Leopoldianum. Revista de Estudos e Comunicações, Santos, v. XXII, n. 60, p. 119-122, abr. 1996.

SIMOES, João Gaspar. Machado de Assis e Eça de Queiroz ou o humorismo e a ironia. Revista do Brasil, Rio de Janeiro, Ano IV, n. 37, p. 1-03, jul. 1941.

SODRÉ, Nelson Werneck. História da Imprensa no Brasil. Rio de Janeiro: Graal, 1977.

TORRES, Antônio. Verdades indiscretas. Rio de Janeiro: Livraria Castilho, 1925.

VERÍSSIMO, José. Letras e literatos. Estudinhos críticos da nossa literatura do dia. 1912-1914. Rio de Janeiro: José Olympio, 1936. 


\section{Resumo}

O presente artigo analisa a obra de Eça de Queirós, enfatizando práticas de leitura e sua recepção no Brasil, com o intuito de demonstrar a extensão dessa recepção e identificar os leitores de seus romances.

\section{Abstract}

The present article analyzes the Eça de Queirós fiction, emphasizing its reading and its reception in Brazil, in order to demonstrate the extension of this reception and identify the readers of his novels. 